\title{
Targeting the osteosarcoma cancer stem cell
}

\author{
Valerie A Siclari, Ling Qin*
}

\begin{abstract}
Osteosarcoma is the most common type of solid bone cancer and the second leading cause of cancer-related death in pediatric patients. Many patients are not cured by the current osteosarcoma therapy consisting of combination chemotherapy along with surgery and thus new treatments are urgently needed. In the last decade, cancer stem cells have been identified in many tumors such as leukemia, brain, breast, head and neck, colon, skin, pancreatic, and prostate cancers and these cells are proposed to play major roles in drug resistance, tumor recurrence, and metastasis. Recent studies have shown evidence that osteosarcoma also possesses cancer stem cells. This review summarizes the current knowledge about the osteosarcoma cancer stem cell including the methods used for its isolation, its properties, and its potential as a new target for osteosarcoma treatment.
\end{abstract}

\section{Introduction}

Osteosarcoma is the most common type of solid bone cancer, mainly arising in children and young adults. About 6 in every million children and 2 in every million adults will develop osteosarcoma [1]. Osteosarcomas most commonly develop in the long bones, in particular the distal femur and proximal tibia. They are often very aggressive (high-grade tumors) with about $20 \%$ of patients presenting with metastases. Osteosarcomas most commonly metastasize to the lung but also can metastasize locally to other sites within the bone. Osteosarcomas are characterized as tumors that produce osteoid. By X-ray, osteosarcomas often appear as tumors associated with mixed osteolytic and osteoblastic bone destruction and a soft tissue mass. They can be histologically classified into three types: osteoblastic, chondroblastic, and fibroblastic (reviewed in [2,3]). Microarray analysis has revealed that there are significant gene expression differences amongst the sub-types. 172 genes were differentially expressed between osteoblastic and non-osteoblastic osteosarcomas [4].

Osteosarcoma is believed to arise from mesenchymal stem cells (MSCs) or osteoprogenitor cells due to a disruption in the osteoblast differentiation pathway $[5,6]$. Genetic instability has made identifying the cause(s) of osteosarcoma development difficult [7]. A number of pathways and inactivating mutations have been proposed to play a role in osteosarcoma development

\footnotetext{
* Correspondence: qinling@mail.med.upenn.edu

Department of Orthopaedic Surgery, University of Pennsylvania School of Medicine, Philadelphia, PA, USA
}

including downregulation of the Wnt signaling pathway and inactivating mutations in p53 and retinoblastoma. However, none of these pathways/mutations have been implicated as main causes of osteosarcoma $[2,6,8]$. Paget's disease and prior irradiation are also risk factors for osteosarcoma [9]. In a study comparing the gene expression of 22 human osteosarcoma tumors to 5 normal human osteoblasts, osteosarcoma tumors had increased expression of RECQL4, SPP1, RUNX2, and IBSP and decreased DOCK5, CDKN1A, RB1, P53, AND LSAMP compared to normal osteoblasts. Increased Runx2 expression was associated with a poor response to chemotherapy [10]. High expression of the cell cycle inhibitor p21/WAF1 has also been proposed to indicate a worse prognosis [11].

Since the 1970s, combination chemotherapy along with limb-sparing surgery has been the main treatment for osteosarcoma. The most commonly used chemotherapeutic regimen includes pre- and post-operative cisplatin and doxorubicin with or without high-dose methotrexate [3]. Many patients develop resistance to this current therapy and tumor recurrence. Five-year patient survival has plateaued at about $70 \%$ for patients with non-metastatic disease and outcome is much worse for patients with metastases [2,12]. Targeting molecules important for tumorigenesis, "targeted therapy", has been an exciting development in cancer treatment in the past ten years. Yet, no such therapy is currently available for osteosarcoma. Today, osteosarcoma remains the second leading cause of cancer-related death for children and young adults [13]
C Biomed Central

두 2010 Siclari and Qin; licensee BioMed Central Ltd. This is an Open Access article distributed under the terms of the Creative Commons Attribution License (http://creativecommons.org/licenses/by/2.0), which permits unrestricted use, distribution, and reproduction in any medium, provided the original work is properly cited. 
and therefore, there is a great need for developing new osteosarcoma treatments.

\section{The Cancer Stem Cell Hypothesis}

The cancer stem cell hypothesis proposes that within a heterogeneous tumor there is a small subpopulation of cells called "cancer stem cells (CSCs)" that are responsible for forming the bulk of the tumor [14-16]. They are similar to stem cells and may arise from the transformation of stem cells or the de-differentiation of non-stem cells. They are quiescent and capable of both selfrenewal and differentiation into all of the cells within a tumor.

The first evidence of the existence of CSCs came from studies of hematological malignancies. In 1994, Lapidot and colleagues showed evidence that only a small percentage of acute myeloid leukemia (AML) cells were capable of initiating leukemia in mice [17]. They found that at least 250,000 peripheral blood cells from AML patients were required for leukemic engraftment in severe combined immunodeficiency (SCID) mice, suggesting that there was only 1 cell per 250,000 cells capable of engraftment. Using fluorescence-activated cell sorting (FACS), leukemic stem cells were isolated as a subpopulation of less than $0.2 \%$ of the total leukemic cells in AML patients with similar cell surface markers $\left(\mathrm{CD} 34^{+} \mathrm{CD}^{-} 8^{-}\right)$to normal hematopoietic stem cells $[17,18]$. Interestingly, only the $\mathrm{CD} 34^{+} \mathrm{CD} 38^{-}$leukemic stem cell population but not the $\mathrm{CD} 34^{+} \mathrm{CD} 38^{+}$or $\mathrm{CD} 34^{-}$ population was able to form AML in SCID mice.

Following the success in hematological malignancies, FACS and magnetic-activated cell sorting (MACS) for stem cell surface markers including CD34, CD138, CD20, CD90, CD133, and CD44 have now been widely employed to identify CSCs in a number of cancers (reviewed in $[15,19])$. However, the use of tissue-specific stem cell markers to identify CSCs is limited by the lack of knowledge of these markers for every tissue type. Other methods to isolate CSCs are based on common characteristics of normal stem cells. These include growth of cells in serum-free, non-adherent sphere assays, serial colony-forming unit assays, sorting of cells for aldehyde dehydrogenase (ALDH) activity, and sorting for side population (SP) cells [15,19]. Although these functional assays are great tools to determine if a population possesses stem cells when normal stem cell surface markers are unknown, one pitfall is that these assays mostly just enrich for CSCs and therefore actually provide a mixed population of cells for study. The best evidence that cells isolated through these methods are true cancer stem cells comes from serial transplantation studies in which sorted cells are grown in xenograft models (typically in non-obese diabetic/severe combined immunodefficiency (NOD/SCID) mice), resorted and retransplanted to form new tumors (reviewed in $[14,15])$.

Using the above mentioned assays, the presence of CSCs has now been identified not just in hematological malignancies but also in a number of solid tumors including breast, brain, skin, lung, colon, pancreatic, liver, head and neck, and prostate cancers [15]. Overall, the identified CSCs are a subpopulation $(<1 \%)$ of the overall tumor cell population [20] and have high tumorigenic potential, requiring much lower numbers of cells to form tumors in mice than non-CSCs (some showing as low as 100 cells being capable of forming tumors in mice) (reviewed in $[14,15]$ ). They not only regrow CSCs when transplanted into mice, but, reform the whole heterogeneous population of tumor cells within these xenograft models. They also have upregulation of genes associated with stem cell maintenance of self-renewal and pluripotency such as Oct4 and Nanog and drug transporters such as ABCG2 [21-26].

Similar to stem cells, evidence suggests that CSCs are resistant to cancer therapies including radiation and chemotherapy. For example, $\mathrm{CD} 133^{+}$glioma stem cells are less sensitive to radiation and undergo less radiation-induced apoptosis than CD133 glioma cells both in vitro and in vivo. In fact, radiation enriches the percentage of $\mathrm{CD}_{133^{+}}$glioma stem cells relative to other tumor cells [27]. $\mathrm{CD} 133^{+}$glioblastoma stem cells are more resistant to the chemotherapeutic agents temozolomide, carboplatin, paclitaxel and etoposide compared to CD133 cells [28]. Neuroblastoma and mouse ovarian cancer SP cells are more resistant to chemotherapeutic agents than non-SP cells $[29,30]$. Paired breast cancer core biopsies obtained from patients with primary breast cancer before and after 12 weeks of chemotherapy found that chemotherapy caused a 3-fold increase in the CD $44^{+} / \mathrm{CD} 24^{-/ \text {low }}$ breast CSC population [31]. CSC characteristics such as quiescence, increased drug-efflux ability, increased DNA repair ability, and increased resistance to apoptosis have been proposed to contribute to CSC resistance to cancer therapies [15]. Therefore, although treatment with chemotherapy or radiation may reduce the bulk of the tumor, it may actually miss the most important cell to target, the cancer stem cell. Following chemotherapy or radiation therapy, CSCs may survive and could begin to differentiate and reform the tumor. Hence, CSCs are proposed to be responsible for chemoresistance, tumor recurrence, and tumor progression in many tumor types $[15,19]$.

Although CSCs may be resistant to chemotherapy, evidence from studies of leukemia has shown that it is possible to find drugs that specifically inhibit the growth of CSCs. For example, the anthracycline idarubicin in combination with the proteasome inhibitor MG-132 induced apoptosis of AML stem cells in vitro and in vivo with 
no effect on normal hematopoietic stem cell viability [32]. Another study found that parthenolide, an inhibitor of $\mathrm{NF} \kappa \mathrm{b}$, had similar effects and inhibited tumorogenesis in mice [33].

Several methods have been proposed to target the CSC [15]. One method is targeting cytotoxic drugs to CSCs using stem cell surface markers. For example, targeting CD33 (an AML stem cell surface marker) with the FDA-approved drug gemtuzumab ozogamicin (Mylotarg), a recombinant humanized anti-CD33 monoclonal antibody conjugated to calicheamicin (a cytotoxic antibiotic), did produce some but low anti-leukemic activity in $\mathrm{CD}_{3} 3^{+}$AML patients 60 years and older who are not eligible for other cytotoxic therapies [34]. Another method is to target the CSC microenvironment, such as the blood vessels in vascular niches. Treatment of U87 glioma cell xenografts with the antiangiogenic inhibitor Bevacizumab (anti-vascular endothelial growth factor (VEGF) monoclonal antibody) significantly decreased the number of vessel-associated $\mathrm{CD}_{133^{+}}$nestin $^{+}$brain cancer stem cells in mice [35]. Induction of CSC differentiation could be another way to eliminate these cells. All-trans retinoic acid induced differentiation of leukemic cells and increased relapsefree and overall survival in acute promyelocytic leukemia patients when given prior to anthracycline treatment [36]. However, patients often quickly develop resistance to retinoids.

\section{Evidence for Cancer Stem Cells in Osteosarcoma}

Since the proposal of the CSC hypothesis, many studies have been performed to identify the osteosarcoma CSC. Currently, there are three methods that have now been employed to enrich for osteosarcoma CSCs including: (1) the sphere culture assay (or sarcosphere assay), (2) cell sorting for CD133, high ALDH activity, SP cells, or CD117 in combination with Stro-1, and (3) identification of cells that express the embryonic stem cell gene Oct4. This review will summarize each of these methods below.

\section{Sphere Culture Assay}

Gibbs et al. (2005) were the first to show that osteosarcomas possess cells with CSC characteristics [37]. When grown in serum-free semi-solid N2 medium with epidermal growth factor (EGF) and fibroblast growth factor basic (FGFb) in low attachment plates, MG-63 human osteosarcoma cells and primary osteosarcoma cells formed spheres at a frequency of 0.1 to $1 \%$. These spheres had increased expression of the embryonic stem cell markers Oct 4 and Nanog compared to adherent cells. Osteosarcoma spheres also had self-renewal ability as dissociation of the spheres produced single cells capable of forming secondary spheres at an equal or higher rate than adherent cells. Consistent with these results, several other groups have also confirmed the ability of osteosarcomas to form spheres [38-40]. The human osteosarcoma cell lines OS99-1, Hu09, MG-63 and Saos-2 and the canine osteosarcoma cell lines D-17, UWOS-1, and UWOS-2 are all capable of forming spheres which express the embryonic stem cell genes Oct 4 and Nanog and therefore have a primitive phenotype. In these experiments, spheres could be reproduced consistently when passaged multiple times and produced adherent cell cultures when returned to normal growth conditions. Interestingly, MG-63 spheres were less sensitive to doxorubicin and cisplatin than adherent cells and had increased expression of the DNA mismatch repair enzyme genes MLH1 and MSH2, suggesting that these sphere cells might confer chemoresistance $[38,41]$.

\section{Cell Sorting \\ A. CD133 (prominin-1)}

CD133 (prominin-1) is a pentaspan membrane glycoprotein used initially as a marker for neuroepithelial stem cells and has been subsequently used as a marker for many CSCs including brain and colon CSCs [42-45]. Recently, Tirino et al. identified a small $\mathrm{CD}_{133^{+}}$population (3-5\%) in the human osteosarcoma cell lines MG63, Saos-2, and U20S with stem cell characteristics [45]. Compared to CD133 cells, these cells had an increased percentage of cells in G2/M phase, were Ki67-positive and had increased in vitro growth, indicating that they are more proliferative. $\mathrm{CD}_{133^{+}}$cells, but not $\mathrm{CD} 133^{-}$ cells, were capable of forming spheres in culture and had an increased ability to form colonies in a soft agar assay. Cells obtained from spheres formed by CD133 ${ }^{+}$ cells were capable of forming new spheres containing both $\mathrm{CD} 133^{-}$and $\mathrm{CD} 133^{+}$cells, indicating that $\mathrm{CD} 133^{+}$ cells can differentiate into CD133- cells. Spheres initially formed from $\mathrm{CD} 133^{+}$cells and passaged 4 to 6 times showed increased expression of Oct4 and CD133. In addition to expressing CD133, the human osteosarcoma cell lines Saos-2, OSA-1, OSA-2, and OSA-3 also express nestin, a marker for neural stem cells and brain CSCs, suggesting that nestin and CD133 might be used as co-markers for identifying osteosarcoma CSCs [46].

\section{B. Hoechst 33342 Dye Exclusion and the Side Population} (SP) cells

SP cells are capable of effluxing the DNA-binding dye Hoechst 33342 using ATP-binding cassette (ABC) transporters. This ability to efflux Hoechst dye was first identified as a characteristic of normal haematopoietic stem cells $[47,48]$ but has subsequently been used to identify CSCs in cancers such as gastrointestinal and ovarian cancer [30,49]. Murase and colleagues screened seven osteosarcoma cell lines including OS2000, KIKU, NY, Huo9, HOS, U20S, and Saos- 2 cells for the presence of 
a side population [50]. Only the NY osteosarcoma cell line demonstrated a small percentage of cells $(0.31 \%)$ with side population characteristics. However, the presence of stem cell characteristics in this population was not confirmed by the authors. Tirino et al. (2008) also attempted to identify SP cells in osteosarcoma. They found that $\mathrm{CD} 133^{+}$Saos- 2 cells do possess a small side population (0.97\%) [45]. These results suggest that sorting for a side population alone is not a good technique to isolate the osteosarcoma CSC.

\section{High Aldehyde Dehydrogenase (ALDH) Activity}

ALDHs are a group of cytosolic enzymes that oxidize intracellular aldehydes into carboxylic acids [51]. High ALDH1 expression has been linked to leukemia, breast, and colon cancer chemoresistance [52-55]. Human and murine hematopoietic stem cells and neural stem and progenitor cells have increased ALDH activity compared to non-stem cells [56-58]. Detection of cells with high ALDH activity identifies CSCs in a number of cancers including breast, liver, colon, and acute myelogenous leukemia [59-62]. Wang et al. demonstrated that while adherent Hu09, Saos-2, and MG-63 cells possess small populations $(1.8 \%, 1.6 \%$, and $0.6 \%$ respectively) with high ALDH activity (ALDH(br)), OS99-1 contained a high percentage (45\%) of ALDH(br) cells [63]. However, OS99-1 ALDH(br) cells isolated from cell cultures did not have increased tumorigenicity compared to cells with low ALDH activity (ALDH(lo)). Interestingly, growth in tumor xenografts dramatically decreased the ALDH(br) cell population in OS99-1 to less than 3\%. These ALDH(br) cells from tumor xenografts had increased proliferation, colony formation ability, expression of the stem cell genes Oct4, Nanog, and Sox-2, and most importantly, increased tumorigenicity when subcutaneously injected into NOD/SCID mice compared to ALDH(lo) cells. Serial transplantation of these ALDH (br) cells showed that they were capable of self-renewal and reforming the bulk of the tumor. In contrast to the results of Wang et al., Honoki et al. showed a larger percentage of MG-63 cells (11\%) with high ALDH activity. MG-63 sphere cells also were enriched for ALDH1 expression [41].

\section{CD117 and Stro-1}

CD117(c-kit) is the receptor for stem cell factor and a known proto-oncoprotein. It is also one of the markers used to isolate CSCs from ovarian cancer [64,65]. Stro-1 is a cell surface marker for mesenchymal stem cells [66]. Adhikari et al. found that sphere cells generated from the mouse osteosarcoma cell lines K7M2, 318-1, and P932 possessed characteristics of CSCs such as having increased tumorigenicity when injected subcutaneously into mice, increased expression of the drug transporter ABCG2, and an ability to differentiate into multiple lineages (osteogenic and adipogenic). The mouse sphere cells also had increased expression of the chemokine receptor CXCR4, a receptor linked to an increased metastatic ability, and an increased percentage of $\mathrm{CD}_{117^{+}}$Stro- $^{+}{ }^{+}$(DP) cells. DP K7M2 and 318-1 mouse osteosarcoma cells were more resistant to the chemotherapeutic doxorubicin than CD117-Stro-1- (DN) and parental cells. Both mouse and human DP osteosarcoma cells had increased expression of ABCG2 and CXCR4 compared to DN cells. DP mouse 318-1, K7M2, and P932 and human KHOS, BCOS, and MNNG/HOS osteosarcoma cells had increased tumorigenicity when subcutaneously injected into nude mice compared to DN cells derived from the same cell line. 318-1 DP cells produced tumors not just with DP cells but also DN and single positive, suggesting that 318-1 DP cells not only self-renew but also can differentiate and reform all of the cells within the tumor. When 318-1 DP cells were injected into the femoral bone marrow cavity of NOD/SCID mice, they had increased primary tumor take and metastasis to the lung. These lung metastases had more cells positive for the markers CD117, Stro-1, ABCG2, and CXCR4 than the primary bone tumor [66], suggesting that the osteosarcoma CSCs are the cells with an increased ability to metastasize to lung.

\section{Oct4}

Oct4 is a central determinant of embryonic stem (ES) cell identity and one of four transcriptional factors which, when introduced together, were sufficient to reprogram differentiated fibroblasts to confer pluripotency indistinguishable from ES cells [67]. Based on the findings that osteosarcoma spheres had increased expression of Oct4, Levings et al. engineered an osteosarcoma cell line (OS521Oct-4p) that stably expressed a human Oct4 promoter-driven GFP reporter [68]. Twenty-four percent of the cells in culture and $67 \%$ of the cells in xenografted tumors were GFP positive. These Oct $4 / \mathrm{GFP}^{+}$cells from xenograft tumors also expressed the MSC markers CD105 and ICAM-1. Moreover, GFP-enriched cells were more than 100 fold more tumorigenic than GFP-depleted cells, capable of forming subcutaneous tumors with less than 300 cells in NOD/ SCID mice and metastasizing to lung. These cells could also differentiate and form Oct $4 / \mathrm{GFP}^{-}$cells.

Overall, the methods mentioned above show evidence that a subpopulation of osteosarcoma cells do exist with cancer stem cell characteristics. One interesting common feature of the CSCs derived from the different isolation methods is that they all have increased expression of genes required for ES cell maintenance (Oct4 and Nanog) $[37,38,45,50,63]$. This is consistent with previous findings that many types of CSCs, including ovarian, prostate, renal carcinoma and Ewing's sarcoma, highly express Oct4 and Nanog $[21,22,24,26]$. However, these 
genes are difficult to use as markers for isolation. Furthermore, most commonly available untransformed human osteosarcoma cell lines, such as Saos-2, MG-63, and U2OS cells, are difficult to grow in animal models, hindering further research to test the in vivo tumorigenic ability of isolated CSCs and confirm their stem cell nature [13].

\section{Cells of Origin for Osteosarcoma Cancer Stem Cells}

CSCs have been proposed to arise either from the transformation of normal stem cells to cancerous stem cells or from the dedifferentiation and transformation of progenitor or terminally-differentiated cells to tumor cells with stem cell-like characteristics [14]. Osteosarcomas are proposed to be a "differentiation-flawed disease", resulting from genetic and epigenetic disruption of the osteoblast differentiation pathway [6]. Evidence for this includes that osteosarcoma cells are similar to the boneforming cell, the osteoblast, since both of these cells produce osteoid, suggesting that osteosarcomas arise from osteoblasts or osteoprogenitors. Osteosarcomas also have histological variability, not only having osteoblastic regions but also chondroblastic or fibroblastic regions [69], indicating that the osteosarcoma cell of origin may be a cell with multipotent potential. Mesenchymal stem cells (MSCs) are multipotent stem cells found in adult bone marrow capable of differentiating into not only osteoblasts but also cartilage, fat, tendon, muscle, and marrow stroma and therefore tumors arising from MSCs could resemble the varied histology of osteosarcomas [70]. Bone marrow-derived MSCs can spontaneously undergo malignant transformation after long-term culture and result in fibrosarcoma formation in vivo [71]. Firefly-luciferase and Dsred-labeled adult mouse MSCs (a cell line derived after non-tumorigenic genetic manipulation and long-term culture of MSCs) formed osteosarcoma-like tumors in mice [72]. Loss of the Cdkn2 locus, aneuploidization, and translocations in MSCs are involved in their malignant transformation [5]. Complete loss of one of the proteins encoded in the cdkn2 locus, CDKN2A/p16, was associated with lower survival in 88 osteosarcoma patients [5]. Therefore, osteosarcomas may arise from either MSCs or osteoprogenitors.

Taking into account the CSC hypothesis, we propose that MSCs might be the cells of origin for osteosarcoma CSCs. Therefore, further understanding of the MSC may aid in the understanding of the osteosarcoma CSC. Currently the markers for isolating MSCs are controversial and not as defined as the hematopoietic stem cell (reviewed in [73]). One of the criteria that the International Society for Cellular Therapy proposed to define a MSC population is that the cells must be "greater than or equal to $95 \%$ positive for CD73 (ecto-5'-nucleotidase), CD90 (Thy-1), and CD105 (endoglin) with no more than $2 \%$ of the cells positive for CD34, CD45, CD11 b or CD14, CD19 or CD79alpha, and HLA-DR" (markers of hematopoietic progenitors, endothelial cells, monocytes, macrophages, B cell markers, and stimulated mesenchymal stem cells) [73]. Other proposed MSC markers include: CD44, CD49a, STRO-1, CD200, CD271, and CD146 [73]. Gibbs et al. found that the MSC markers Stro-1, CD105, and CD44 were expressed in $2-10 \%, 30-50 \%$, and $75-100 \%$ of osteosarcoma cells in culture, respectively [37]. Tirino et al. (2008) showed that nearly $100 \%$ of MG-63, U20S and Saos-2 cells express the MSC markers CD90, CD44, and CD29 [45,74]. Only one of these proposed mesenchymal stem cell markers, Stro-1, has been used to successfully isolate osteosarcoma cells with CSC characteristics. Stro-1 in combination with CD117 isolated cells with CSC characteristics from mouse and human osteosarcoma cells [66]. However, since the majority of osteosarcoma cells are positive for many of these proposed MSC markers, markers such as CD90, CD44, and CD29 may not be useful markers to isolate the osteosarcoma CSC. Identifying the novel and specific markers for MSCs will aid in identifying the osteosarcoma CSC.

\section{Possible Niche for Osteosarcoma Cancer Stem Cells}

Normal stem cells are found within niches (microenvironments) that support the stem cell. Stem cells and niche cells interact with each other via adhesion molecules and molecular signals that are important for maintenance of stem cell self-renewal, differentiation, and quiescence [75]. For example, hematopoietic stem cells depend on interactions with osteoblasts in osteoblastic niches and interactions with endothelial cells in vascular niches in the bone marrow to maintain their stem cell characteristics [20].

Like normal stem cells, CSCs also require a microenvironmental niche to maintain stemness. CSCs may form their own niche or take over normal stem cell niches $[20,76,77]$. There is evidence that brain tumor cells reside in vascular niches. The putative nestin ${ }^{+} \mathrm{CD} 133^{+}$brain CSCs were found next to capillaries in brain tumors and adhere to endothelial cells [35]. Co-injection of $\mathrm{CD}_{133^{+}}$human medulloblastoma cells with endothelial cells into mice increased tumor formation [35]. If CSCs require environmental signals and cell interactions within niches to maintain their stem cell properties, this suggests that when studying the cancer stem cell, the environment in which the cells are studied is very important. Differences in behavior of osteosarcoma CSCs grown in vitro compared to in vivo have been observed. For example, although in vivo the CSC is characterized by being quiescent, in vitro osteosarcoma CSCs are more proliferative than 
the non-CSCs [20,37]. OS99-1 cells isolated with high ALDH activity only had the behavior of CSCs when cells were isolated from subcutaneous tumors and not from adherent in vitro cultures [63]. Therefore, when studying CSCs, it may be important to only use models that as closely as possible recapitulate the normal environment.

The osteosarcoma CSC niche has not been defined. However, if osteosarcoma CSCs arise from MSCs, it is feasible that they may reside within the proposed MSC niche, a perivascular niche (reviewed in [73]). The location of MSCs within perivascular niches is proposed to support the migration of MSCs in response to injury or disease [73]. Similarly, location within a perivascular niche may support the metastasis of osteosarcomas to lung.

Since the local environment affects the behavior of CSCs, studying osteosarcoma CSCs in the context of its local environment, the bone, may be important for determining how to target osteosarcoma CSCs for treatment. The bone is a unique environment with properties that could alter the behavior of a CSC. For example, the bone is a hypoxic environment [78]. Activation of the hypoxia signaling pathway activates many pathways important for stem cell maintenance and, interestingly, hypoxia increases the number of brain CSCs [79]. Therefore, hypoxia might play a role in regulating osteosarcoma CSCs. The bone matrix is also rich in growth factors [80]. Alterations in bone remodeling due to the development of osteosarcoma could cause release of growth factors, such as transforming growth factor beta (TGF $\beta$ ) or bone morphogenetic proteins (BMPs) that are capable of influencing stem cell maintenance. The TGF $\beta$ signaling pathway is upregulated in breast CSCs and its inhibition induced breast CSC differentiation in vitro [81]. BMPs induce differentiation of brain tumor stem cells in vivo [82]. BMPs may not have a similar effect on osteosarcomas since BMPS do not induce differentiation of osteosarcomas but promote growth in vivo [83]. Bone also contains the chemokine ligand SDF-1 [84] and osteosarcomas express its receptor, CXCR4 [85]. The CXCR4/SDF-1 signaling pathway is involved in the maintenance of hematopoietic stem cell numbers [86]. Interaction of bone matrix-derived SDF-1 with CXCR4 receptors could be involved in maintaining the osteosarcoma CSC.

The orthotopic osteosarcoma model is produced by injecting osteosarcoma cells into the long bones of immuno-compromised mice. Despite the importance of the local environment in CSC behavior, to date, only one group has published results looking at the growth of potential osteosarcoma CSCs in an orthotopic model [66]. Adhikara et al. showed the difference in growth of CD $117^{+}$Stro- $1^{+}$mouse osteosarcoma cells compared to $\mathrm{CD} 17^{-}{ }^{-}$tro- $1^{-}$cells in the femur of NOD/SCID mice.
However, no one has studied human osteosarcoma CSCs in an orthotopic model. This is most likely because there are currently very few reports of untransformed human osteosarcoma cell lines that are commercially available and able to grow within this model [13]. Further development of either orthotopic osteosarcoma models or spontaneous osteosarcoma models is important for the study of the osteosarcoma CSC and its niche.

\section{Conclusions and Perspectives}

There is compelling evidence that osteosarcoma tumors possess cancer stem cells. This will have a great impact on the design and evaluation of novel treatments for osteosarcoma. The current treatment, chemotherapy together with surgical removal, can only cure around $70 \%$ of osteosarcoma patients because of chemoresistance $[2,12]$. Osteosarcoma CSCs are proposed to be responsible for this chemoresistance and therefore should be considered as a major target for developing novel treatments (Figure 1) $[2,12,38,87]$. Current treatment with chemotherapy shrinks the bulk of the tumor but osteosarcoma CSCs remain unharmed. Following treatment, these CSCs can self-renew and reform the bulk of the tumor leading to tumor recurrence (Figure 1A). However, if a CSC-targeted therapy is incorporated, CSCs would be killed, eliminating the cells capable of reforming the bulk of the tumor. Post-therapy, any remaining non-CSCs could divide, but unlike CSCs, non-CSCs have limited proliferative capacity and would eventually die out (Figure 1B). Moreover, since preliminary animal data suggest that there are more CSCs in lung metastasis samples and that CSCs have an increased ability to metastasize to the lung [66], CSCtargeted therapy could also be an effective treatment to reduce osteosarcoma lung metastases. Therefore, we propose that a combination of chemotherapy, CSCtargeted therapy, and surgical removal of tumor will improve patient outcomes.

In order to develop CSC-targeted therapy, it is important to be able to specifically isolate the CSCs. Although the methods utilized to detect the osteosarcoma CSC show populations with enriched stem cell-like characteristics, no specific markers for the osteosarcoma CSC have been established. One immediate question is: What are the correct markers to isolate the osteosarcoma CSC? Further understanding of the MSC, a putative cell-of-origin for the osteosarcoma CSC, could aid in successful specific isolation of the osteosarcoma CSC.

Once we specifically isolate the osteosarcoma CSC, another question is: How can these cells be targeted and killed? One way to detect therapeutic targets in CSCs is to determine how these cells differ genetically from other non-CSCs using microarray analyses. One recent 


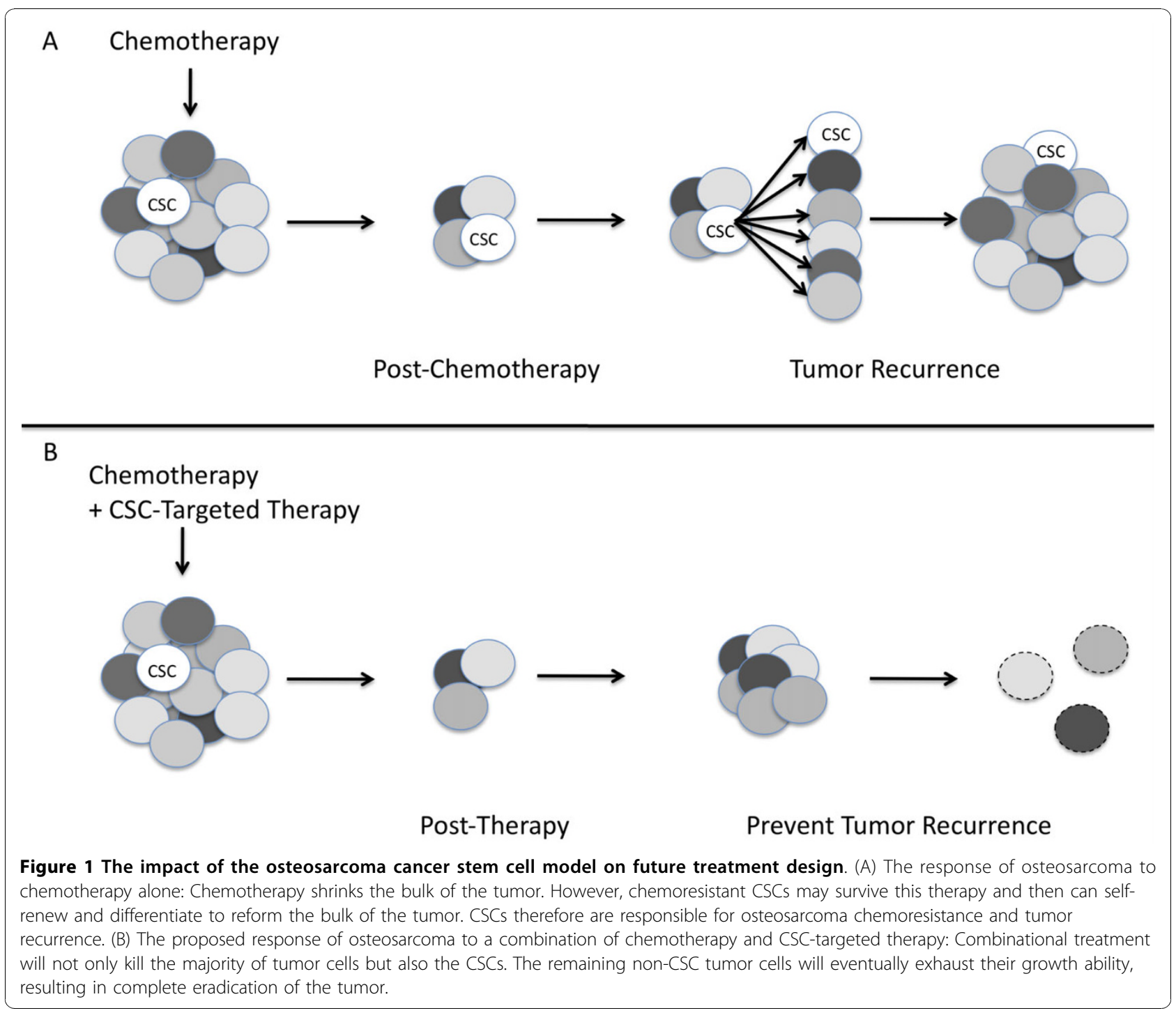

study found that MG-63 spheres have increased expression of the DNA repair enzyme genes MLH1 and MSH2 compared to adherent cells and increased resistance to the common osteosarcoma therapeutics cisplatin and doxorubicin [38]. Treatment of these spheres with caffeine, a DNA repair enzyme inhibitor, along with doxorubicin or cisplatin increased the inhibition of cell growth more than treatment with these chemotherapeutics alone. Therefore, the addition of drugs that increase sensitivity of the CSCs to current chemotherapy regimens could be important for the improvement of current therapy.

Although the CSC may be a great new target for cancer therapy, one major problem with the CSC as a therapeutic target is that it has many similar properties to normal stem cells. This leads to the third question: How do osteosarcoma CSCs differ from normal stem cells? It will be important to monitor the effect of proposed CSC therapeutics on normal stem cells to ensure a limited amount of non-specific toxicity. Further understanding of the osteosarcoma CSC will aid in determining how to target it. Microarray analyses can determine genes that are upregulated in the osteosarcoma CSC compared to non-CSCs but not in the normal stem cell population. High-throughput screening could identify drugs that CSCs are sensitive to, while leaving the normal stem cells unharmed. Ultimately, the development of new therapies targeting the osteosarcoma CSC requires the monitoring of any effect on normal stem cells as a potential side-effect.

\section{Acknowledgements}

The authors would like to thank Drs. Richard Lackman and Andrea Evenski for providing key clinical insights into osteosarcoma. This publication was 
made possible by a NOA Schwartz Siris Research Award from the Bone and Cancer Foundation (to LQ) and a training grant in Cancer Pharmacology (R25 CA101871-07) from the National Cancer Institute (to VS).

\section{Authors' contributions}

VS and LQ both reviewed the literature and decided upon the content of this review. VS wrote the first draft and both VS and LQ edited the manuscript. All authors read and approved the final manuscript.

\section{Competing interests}

The authors declare that they have no competing interests.

Received: 5 May 2010 Accepted: 27 October 2010

Published: 27 October 2010

\section{References}

1. Raymond AK: Conventional Osteosarcoma. Lyon: IARC Press; 2002.

2. Longhi A, Errani C, De Paolis M, Mercuri M, Bacci G: Primary bone osteosarcoma in the pediatric age: state of the art. Cancer Treat Rev 2006 32:423-436.

3. Wittig JC, Bickels J, Priebat D, Jelinek J, Kellar-Graney K, Shmookler B, Malawer MM: Osteosarcoma: a multidisciplinary approach to diagnosis and treatment. Am Fam Physician 2002, 65:1123-1132.

4. Kubista B, Klinglmueller F, Bilban M, Pfeiffer M, Lass R, Giurea A, Funovics PT, Toma C, Dominkus M, Kotz R, et al: Microarray analysis identifies distinct gene expression profiles associated with histological subtype in human osteosarcoma. Int Orthop 2010.

5. Mohseny AB, Szuhai K, Romeo S, Buddingh EP, Briaire-de Bruijn I, de Jong $D$, van Pel M, Cleton-Jansen AM, Hogendoorn PC: Osteosarcoma originates from mesenchymal stem cells in consequence of aneuploidization and genomic loss of Cdkn2. J Pathol 2009, 219:294-305

6. Tang N, Song WX, Luo J, Haydon RC, He TC: Osteosarcoma development and stem cell differentiation. Clin Orthop Relat Res 2008, 466:2114-2130.

7. Hogendoorn PC, Bove J, Karperien M, Cleton-Jansen AM: Skeletogenesis: Genetics. London: Nature Publishing Group; 2003.

8. Cleton-Jansen AM, Anninga JK, Briaire-de Bruijn $\mathbb{I H}$, Romeo S, Oosting J, Egeler RM, Gelderblom H, Taminiau AH, Hogendoorn PC: Profiling of highgrade central osteosarcoma and its putative progenitor cells identifies tumourigenic pathways. Br J Cancer 2009, 101:1909-1918.

9. Fuchs B, Pritchard DJ: Etiology of osteosarcoma. Clin Orthop Relat Res 2002, 40-52.

10. Sadikovic B, Thorner P, Chilton-Macneill S, Martin JW, Cervigne NK, Squire J, Zielenska M: Expression analysis of genes associated with human osteosarcoma tumors shows correlation of RUNX2 overexpression with poor response to chemotherapy. BMC Cancer 2010, 10:202.

11. Won KY, Kim YW, Park YK: Expression of Smad and its signalling cascade in osteosarcoma. Pathology 2010, 42:242-247.

12. Ta HT, Dass CR, Choong PF, Dunstan DE: Osteosarcoma treatment: state of the art. Cancer Metastasis Rev 2009, 28:247-263.

13. Ek ET, Dass CR, Choong PF: Commonly used mouse models of osteosarcoma. Crit Rev Oncol Hematol 2006, 60:1-8.

14. Clarke MF, Dick JE, Dirks PB, Eaves CJ, Jamieson CH, Jones DL, Visvader J, Weissman IL, Wahl GM: Cancer stem cells-perspectives on current status and future directions: AACR Workshop on cancer stem cells. Cancer Res 2006, 66:9339-9344.

15. Ischenko I, Seeliger H, Schaffer M, Jauch KW, Bruns CJ: Cancer stem cells: how can we target them? Curr Med Chem 2008, 15:3171-3184.

16. Koch $U$, Krause M, Baumann M: Cancer stem cells at the crossroads of current cancer therapy failures-Radiation oncology perspective. Semin Cancer Biol 2010, 20(2):116-24.

17. Lapidot T, Sirard C, Vormoor J, Murdoch B, Hoang T, Caceres-Cortes J, Minden M, Paterson B, Caligiuri MA, Dick JE: A cell initiating human acute myeloid leukaemia after transplantation into SCID mice. Nature 1994, 367:645-648.

18. Bonnet D, Dick JE: Human acute myeloid leukemia is organized as a hierarchy that originates from a primitive hematopoietic cell. Nat Med 1997, 3:730-737.

19. Tang C, Ang BT, Pervaiz S: Cancer stem cell: target for anti-cancer therapy. FASEB J 2007, 21:3777-3785.

20. Iwasaki H, Suda T: Cancer stem cells and their niche. Cancer Sci 2009, 100:1166-1172.
21. Bae KM, Su Z, Frye C, McClellan S, Allan RW, Andrejewski JT, Kelley V, Jorgensen M, Steindler DA, Vieweg J, Siemann DW: Expression of pluripotent stem cell reprogramming factors by prostate tumor initiating cells. J 2010, 183:2045-2053.

22. Bussolati B, Bruno S, Grange C, Ferrando U, Camussi G: Identification of a tumor-initiating stem cell population in human renal carcinomas. Faseb $J$ 2008, 22:3696-3705, Epub 2008 Jul 3699

23. Chiou SH, Yu CC, Huang CY, Lin SC, Liu CJ, Tsai TH, Chou SH, Chien CS, $\mathrm{Ku} \mathrm{HH}$, LO JF: Positive correlations of Oct-4 and Nanog in oral cancer stem-like cells and high-grade oral squamous cell carcinoma. Clin Cancer Res 2008, 14:4085-4095.

24. Hu L, McArthur C, Jaffe RB: Ovarian cancer stem-like side-population cells are tumourigenic and chemoresistant. $\mathrm{Br} J$ Cancer 2010, 102:1276-1283.

25. Liu T, Xu F, Du X, Lai D, Zhao Y, Huang Q, Jiang L, Huang W, Cheng W, Liu Z: Establishment and characterization of multi-drug resistant, prostate carcinoma-initiating stem-like cells from human prostate cancer cell lines 22RV1. Mol Cell Biochem 2010, 340(1-2):265-73.

26. Suva ML, Riggi N, Stehle JC, Baumer K, Tercier S, Joseph JM, Suva D, Clement V, Provero P, Cironi $L$, et al: Identification of cancer stem cells in Ewing's sarcoma. Cancer Res 2009, 69:1776-1781.

27. Bao $S$, Wu Q, McLendon RE, Hao Y, Shi Q, Hjelmeland AB, Dewhirst MW, Bigner DD, Rich JN: Glioma stem cells promote radioresistance by preferential activation of the DNA damage response. Nature 2006, 444:756-760.

28. Liu G, Yuan X, Zeng Z, Tunici P, Ng H, Abdulkadir IR, Lu L, Irvin D, Black KL, Yu JS: Analysis of gene expression and chemoresistance of CD133+ cancer stem cells in glioblastoma. Mol Cancer 2006, 5:67.

29. Hirschmann-Jax C, Foster AE, Wulf GG, Nuchtern JG, Jax TW, Gobel U, Goodell MA, Brenner MK: A distinct "side population" of cells with high drug efflux capacity in human tumor cells. Proc Natl Acad Sci USA 2004, 101:14228-14233.

30. Szotek PP, Pieretti-Vanmarcke R, Masiakos PT, Dinulescu DM, Connolly D, Foster R, Dombkowski D, Preffer F, Maclaughlin DT, Donahoe PK: Ovarian cancer side population defines cells with stem cell-like characteristics and Mullerian Inhibiting Substance responsiveness. Proc Natl Acad Sci USA 2006, 103:11154-11159.

31. Li X, Lewis MT, Huang J, Gutierrez C, Osborne CK, Wu MF, Hilsenbeck SG, Pavlick A, Zhang X, Chamness GC, et al: Intrinsic resistance of tumorigenic breast cancer cells to chemotherapy. J Natl Cancer Inst 2008, 100:672-679, Epub 2008 Apr 2029.

32. Guzman ML, Swiderski CF, Howard DS, Grimes BA, Rossi RM, Szilvassy SJ, Jordan CT: Preferential induction of apoptosis for primary human leukemic stem cells. Proc Natl Acad Sci USA 2002, 99:16220-16225.

33. Guzman ML, Rossi RM, Karnischky L, Li X, Peterson DR, Howard DS, Jordan $C T$ : The sesquiterpene lactone parthenolide induces apoptosis of human acute myelogenous leukemia stem and progenitor cells. Blood 2005, 105:4163-4169.

34. Tsimberidou AM, Giles FJ, Estey E, O'Brien S, Keating MJ, Kantarjian HM: The role of gemtuzumab ozogamicin in acute leukaemia therapy. $\mathrm{Br} J$ Haematol 2006, 132:398-409.

35. Calabrese C, Poppleton H, Kocak M, Hogg TL, Fuller C, Hamner B, Oh EY, Gaber MW, Finklestein D, Allen M, et al: A perivascular niche for brain tumor stem cells. Cancer Cell 2007, 11:69-82.

36. Warrell RP Jr: Retinoid resistance in acute promyelocytic leukemia: new mechanisms, strategies, and implications. Blood 1993, 82:1949-1953.

37. Gibbs CP, Kukekov VG, Reith JD, Tchigrinova O, Suslov ON, Scott EW, Ghivizzani SC, Ignatova TN, Steindler DA: Stem-like cells in bone sarcomas: implications for tumorigenesis. Neoplasia 2005, 7:967-976.

38. Fujii H, Honoki K, Tsujiuchi T, Kido A, Yoshitani K, Takakura Y: Sphereforming stem-like cell populations with drug resistance in human sarcoma cell lines. Int J Oncol 2009, 34:1381-1386.

39. Wang L, Park P, Lin CY: Characterization of stem cell attributes in human osteosarcoma cell lines. Cancer Biol Ther 2009, 8.

40. Wilson H, Huelsmeyer M, Chun R, Young KM, Friedrichs K, Argyle DJ: Isolation and characterisation of cancer stem cells from canine osteosarcoma. Vet J 2008, 175:69-75.

41. Honoki K, Fujii H, Kubo A, Kido A, Mori T, Tanaka Y, Tsujiuchi T: Possible involvement of stem-like populations with elevated ALDH1 in sarcomas for chemotherapeutic drug resistance. Oncol Rep 2010, 24:501-505. 
42. Fargeas CA, Corbeil D, Huttner WB: AC133 antigen, CD133, prominin-1, prominin-2, etc.: prominin family gene products in need of a rational nomenclature. Stem Cells 2003, 21:506-508.

43. Ricci-Vitiani L, Lombardi DG, Pilozzi E, Biffoni M, Todaro M, Peschle C, De Maria R: Identification and expansion of human colon-cancer-initiating cells. Nature 2007, 445:111-115

44. Singh SK, Hawkins C, Clarke ID, Squire JA, Bayani J, Hide T, Henkelman RM Cusimano MD, Dirks PB: Identification of human brain tumour initiating cells. Nature 2004, 432:396-401.

45. Tirino V, Desiderio V, d'Aquino R, De Francesco F, Pirozzi G, Graziano A, Galderisi U, Cavaliere C, De Rosa A, Papaccio G, Giordano A: Detection and characterization of CD133+ cancer stem cells in human solid tumours. PLoS One 2008, 3:e3469.

46. Veselska R, Hermanova M, Loja T, Chlapek P, Zambo I, Vesely K, Zitterbart K, Sterba J: Nestin expression in osteosarcomas and derivation of nestin/ CD133 positive osteosarcoma cell lines. BMC Cancer 2008, 8:300.

47. Goodell MA, Brose K, Paradis G, Conner AS, Mulligan RC: Isolation and functional properties of murine hematopoietic stem cells that are replicating in vivo. J Exp Med 1996, 183:1797-1806.

48. Zhou S, Morris JJ, Barnes Y, Lan L, Scheutz JD, Sorrentino BP: Bcrp1 gene expression is required for normal numbers of side population stem cells in mice, and confers relation protection to mitoxantrone in hematopoietic cells in vivo. Proc Natl Acad Sci USA 2002, 99:12339-12344.

49. Haraguchi N, Utsunomiya T, Inoue H, Tanaka F, Mimori K, Barnard GF, Mori M: Characterization of a side population of cancer cells from human gastrointestinal system. Stem Cells 2006, 24:506-513.

50. Murase M, Kano M, Tsukahara T, Takahashi A, Torigoe T, Kawaguchi S, Kimura S, Wada T, Uchihashi $Y$, Kondo T, et al: Side population cells have the characteristics of cancer stem-like cells/cancer-initiating cells in bone sarcomas. Br J Cancer 2009, 101:1425-1432.

51. Vasiliou V, Pappa A, Petersen DR: Role of aldehyde dehydrogenases in endogenous and xenobiotic metabolism. Chem Biol Interact 2000, 129:1-19.

52. Bao F, Polk P, Nordberg ML, Veillon DM, Sun A, Deininger M, Murray D, Andersson BS, Munker R: Comparative gene expression analysis of a chronic myelogenous leukemia cell line resistant to cyclophosphamide using oligonucleotide arrays and response to tyrosine kinase inhibitors. Leuk Res 2007, 31:1511-1520.

53. Chuthapisith S, Eremin J, El-Sheemey M, Eremin O: Breast cancer chemoresistance: emerging importance of cancer stem cells. Surg Oncol 2010, 19:27-32.

54. Duester $\mathrm{G}$ : Families of retinoid dehydrogenases regulating vitamin $\mathrm{A}$ function: production of visual pigment and retinoic acid. Eur J Biochem 2000, 267:4315-4324

55. Dylla SJ, Beviglia L, Park IK, Chartier C, Raval J, Ngan L, Pickell K, Aguilar J, Lazetic S, Smith-Berdan S, et al: Colorectal cancer stem cells are enriched in xenogeneic tumors following chemotherapy. PLoS One 2008, 3:e2428.

56. Hess DA, Wirthlin L, Craft TP, Herrbrich PE, Hohm SA, Lahey R, Eades WC, Creer $\mathrm{MH}$, Nolta JA: Selection based on CD133 and high aldehyde dehydrogenase activity isolates long-term reconstituting human hematopoietic stem cells. Blood 2006, 107:2162-2169.

57. Corti S, Locatelli F, Papadimitriou D, Donadoni C, Salani S, Del Bo R Strazzer S, Bresolin N, Comi GP: Identification of a primitive brain-derived neural stem cell population based on aldehyde dehydrogenase activity. Stem Cells 2006, 24:975-985.

58. Armstrong L, Stojkovic M, Dimmick I, Ahmad S, Stojkovic P, Hole N, Lako M: Phenotypic characterization of murine primitive hematopoietic progenitor cells isolated on basis of aldehyde dehydrogenase activity. Stem Cells 2004, 22:1142-1151.

59. Cheung AM, Wan TS, Leung JC, Chan LY, Huang H, Kwong YL, Liang R, Leung AY: Aldehyde dehydrogenase activity in leukemic blasts defines a subgroup of acute myeloid leukemia with adverse prognosis and superior NOD/SCID engrafting potential. Leukemia 2007, 21:1423-1430.

60. Ginestier C, Hur MH, Charafe-Jauffret E, Monville F, Dutcher J, Brown M, Jacquemier J, Viens P, Kleer CG, Liu S, et al: ALDH1 is a marker of normal and malignant human mammary stem cells and a predictor of poor clinical outcome. Cell Stem Cell 2007, 1:555-567.

61. Huang EH, Hynes MJ, Zhang T, Ginestier C, Dontu G, Appelman H, Fields JZ, Wicha MS, Boman BM: Aldehyde dehydrogenase 1 is a marker for normal and malignant human colonic stem cells (SC) and tracks SC overpopulation during colon tumorigenesis. Cancer Res 2009, 69:3382-3389.

62. Ma S, Chan KW, Lee TK, Tang KH, Wo JY, Zheng BJ, Guan XY: Aldehyde dehydrogenase discriminates the CD133 liver cancer stem cell populations. Mol Cancer Res 2008, 6:1146-1153.

63. Wang L, Park P, Zhang H, La Marca F, Lin CY: Prospective identification of tumorigenic osteosarcoma cancer stem cells in OS99-1 cells based on high aldehyde dehydrogenase activity. Int J Cancer 2010.

64. Zhang S, Balch C, Chan MW, Lai HC, Matei D, Schilder JM, Yan PS, Huang TH, Nephew KP: Identification and characterization of ovarian cancer-initiating cells from primary human tumors. Cancer Res 2008, 68:4311-4320

65. Ma L, Lai D, Liu T, Cheng W, Guo L: Cancer stem-like cells can be isolated with drug selection in human ovarian cancer cell line SKOV3. Acta Biochim Biophys Sin (Shanghai) 2010.

66. Adhikari AS, Agarwal N, Wood BM, Porretta C, Ruiz B, Pochampally RR, Iwakuma T: CD117 and Stro-1 identify osteosarcoma tumor-initiating cells associated with metastasis and drug resistance. Cancer Res 2010, 70:4602-4612.

67. Takahashi K, Yamanaka S: Induction of pluripotent stem cells from mouse embryonic and adult fibroblast cultures by defined factors. Cell 2006 126:663-676.

68. Levings PP, McGarry SV, Currie TP, Nickerson DM, McClellan S, Ghivizzani SC, Steindler DA, Gibbs CP: Expression of an exogenous human Oct-4 promoter identifies tumor-initiating cells in osteosarcoma. Cancer Res 2009, 69:5648-5655.

69. Kansara M, Thomas DM: Molecular pathogenesis of osteosarcoma. DNA Cell Biol 2007, 26:1-18.

70. Pittenger MF, Mackay AM, Beck SC, Jaiswal RK, Douglas R, Mosca JD, Moorman MA, Simonetti DW, Craig S, Marshak DR: Multilineage potential of adult human mesenchymal stem cells. Science 1999, 284:143-147.

71. Miura M, Miura Y, Padilla-Nash HM, Molinolo AA, Fu B, Patel V, Seo BM, Sonoyama W, Zheng JJ, Baker CC, et al: Accumulated chromosomal instability in murine bone marrow mesenchymal stem cells leads to malignant transformation. Stem Cells 2006, 24:1095-1103.

72. Tolar J, Nauta AJ, Osborn MJ, Panoskaltsis Mortari A, McElmurry RT, Bell S, Xia L, Zhou N, Riddle M, Schroeder TM, et al: Sarcoma derived from cultured mesenchymal stem cells. Stem Cells 2007, 25:371-379.

73. Kuhn NZ, Tuan RS: Regulation of stemness and stem cell niche of mesenchymal stem cells: implications in tumorigenesis and metastasis. $J$ Cell Physiol 2010, 222:268-277.

74. Di Fiore R, Santulli A, Ferrante RD, Giuliano M, De Blasio A, Messina C, Pirozzi $G$, Tirino $V$, Tesoriere $G$, Vento R: Identification and expansion of human osteosarcoma-cancer-stem cells by long-term 3aminobenzamide treatment. J Cell Physiol 2009, 219:301-313.

75. Voog J, Jones DL: Stem cells and the niche: a dynamic duo. Cell 2010, 6:103-115

76. Colmone A, Amorim M, Pontier AL, Wang S, Jablonski E, Sipkins DA: Leukemic cells create bone marrow niches that disrupt the behavior of normal hematopoietic progenitor cells. Science 2008, 322:1861-1865.

77. Logothetis CJ, Lin SH: Osteoblasts in prostate cancer metastasis to bone. Nat Rev Cancer 2005, 5:21-28.

78. Kingsley LA, Fournier PG, Chirgwin JM, Guise TA: Molecular biology of bone metastasis. Mol Cancer Ther 2007, 6:2609-2617.

79. Heddleston JM, Li Z, Lathia JD, Bao S, Hjelmeland AB, Rich JN: Hypoxia inducible factors in cancer stem cells. Br J Cancer 102:789-795.

80. Siclari VA, Guise TA, Chirgwin JM: Molecular interactions between breast cancer cells and the bone microenvironment drive skeletal metastases. Cancer Metastasis Rev 2006, 25:621-633.

81. Shipitsin M, Campbell LL, Argani P, Weremowicz S, Bloushtain-Qimron N Yao J, Nikolskaya T, Serebryiskaya T, Beroukhim R, Hu M, et al: Molecular definition of breast tumor heterogeneity. Cancer Cell 2007, 11:259-273.

82. Piccirillo SG, Reynolds BA, Zanetti N, Lamorte G, Binda E, Broggi G, Brem H Olivi A, Dimeco F, Vescovi AL: Bone morphogenetic proteins inhibit the tumorigenic potential of human brain tumour-initiating cells. Nature 2006, 444:761-765

83. Luo $X$, Chen J, Song WX, Tang N, Luo J, Deng ZL, Sharff KA, He G, Bi Y, $\mathrm{He} B$, et al: Osteogenic BMPs promote tumor growth of human osteosarcomas that harbor differentiation defects. Lab Invest 2008, 88:1264-1277. 
84. Sloan EK, Anderson RL: Genes involved in breast cancer metastasis to bone. Cell Mol Life Sci 2002, 59:1491-1502.

85. Lin F, Zheng SE, Shen Z, Tang LN, Chen P, Sun YJ, Zhao H, Yao Y: Relationships between levels of CXCR4 and VEGF and blood-borne metastasis and survival in patients with osteosarcoma. Med Oncol 2010.

86. Sugiyama T, Kohara H, Noda M, Nagasawa T: Maintenance of the hematopoietic stem cell pool by CXCL12-CXCR4 chemokine signaling in bone marrow stromal cell niches. Immunity 2006, 25:977-988.

87. Gillette JM, Nielsen-Preiss SM: Cancer stem cells: Seeds of growth in osteosarcoma. Cancer Biol Ther 2009, 8.

doi:10.1186/1749-799X-5-78

Cite this article as: Siclari and Qin: Targeting the osteosarcoma cancer stem cell. Journal of Orthopaedic Surgery and Research 2010 5:78.

Submit your next manuscript to BioMed Central and take full advantage of:

- Convenient online submission

- Thorough peer review

- No space constraints or color figure charges

- Immediate publication on acceptance

- Inclusion in PubMed, CAS, Scopus and Google Scholar

- Research which is freely available for redistribution

Submit your manuscript at www.biomedcentral.com/submit 